\title{
EL DERECHO PARLAMENTARIO EN MÉXICO A UN SIGLO DE VIGENCIA DE LA CONSTITUCIÓN DE 1917. ANÁLISIS DE AVANCES Y RETROCESOS
}

PARLIAMENTARY LAW IN MEXICO TO A CENTURy OF VALIDITY OF THE CONSTITUTION OF 1917. ANALYSIS OF PROGRESS AND REGRESSIONS

EFRÉN ChÁVEZ HERNÁNDEZ ${ }^{1}$

\begin{abstract}
Resumen: El presente artículo aborda un estudio comparativo de la reglamentación del Poder Legislativo en México en el texto original de la Constitución de 1917 y el texto vigente a mayo de 2019. Mediante el derecho parlamentario, se analizan reformas que a juicio del autor han sido benéficas para la democracia y el equilibrio de poderes en México, y otras que, de acuerdo al autor, han resultado retrocesos en este camino. Mediante una reflexión histórico-comparada de los cambios al Congreso General de los Estados Unidos en este siglo de vigencia de la Constitución, se busca obtener conclusiones sobre la utilidad o no de los mismos, para la consolidación de la democracia. Finalmente, se proponen algunas ideas para mejorar la institución representativa en México.
\end{abstract}

Palabras clave: Poder Legislativo; Texto original Constitución 1917; Reforma constitucional; Control parlamentario.

Abstract: This article addresses a comparative study of the regulation of the Legislative Power in Mexico in the original text of the Constitution of 1917 and the current text to May 2019. Through parliamentary law, reforms are analyzed that in the opinion of the author have been beneficial for democracy and the balance of powers in Mexico, and others that, according to the author, have been setbacks in this way. Some ideas are proposed to improve the representative institution in Mexico.

${ }^{1}$ Doctor en Derecho por el Programa de Posgrado en Derecho de la Universidad Nacional Autónoma de México (UNAM). Académico de tiempo completo en el Instituto de Investigaciones Jurídicas y profesor de la Facultad de Derecho de la UNAM. Investigador Nacional del Sistema Nacional de Investigadores de CONACYT. <efren.chavez@unam.mx> ORCID: https://orcid.org/0000-0001-9212-2950. Fecha de recepción: 13 de junio de 2019; fecha de aprobación: 24 de octubre de 2019. 
Keywords: Legislative Power; Original text Constitution 1917; Constitutional reform; Parliamentary control.

Sumario: I. Notas introductorias; II. El Poder Legislativo en el texto original de la Constitución de 1917; III. Cien años de cambios en el derecho parlamentario mexicano; IV. Perspectivas; V. Conclusiones; VI. Fuentes.

\section{Notas introductorias}

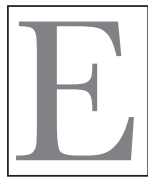

1 derecho parlamentario es la rama derivada del derecho constitucional encargada del estudio de la organización, funcionamiento e integración del órgano representativo denominado Parlamento o Poder Legislativo en un Estado específico, así como de las relaciones de dicho órgano con otros entes.

La regulación del parlamento o Poder Legislativo se encuentra en:

1) la Constitución, como norma fundamental y sobre la que debe sustentarse todo ordenamiento;

2) los Tratados Internacionales, como norma aplicable después de la Constitución;

3) la legislación ordinaria, es decir las leyes expedidas por el Congreso General;

4) la jurisprudencia;

5) los reglamentos aprobados por el Congreso General;

6) las disposiciones emitidas por cada una de las cámaras en particular;

7) los acuerdos parlamentarios aprobados por el pleno de las cámaras;

8) las resoluciones de los órganos rectores de las cámaras, en uso de las facultades;

9) los usos, prácticas y costumbres parlamentarias; y

10) la doctrina, como fuente supletoria de las anteriores. ${ }^{2}$

${ }^{2}$ Para mayor abundamiento sobre el derecho parlamentario puede consultarse: Pedroza de la Llave, Susana Thalía, El Congreso General Mexicano. Análisis Sobre su Evolución y Funcionamiento Actual, México, Editorial Porrúa, 2003; Chávez Hernández, Efrén, El derecho parlamentario estatal mexicano: análisis y propuesta de reforma, 
En este estudio presentaré cómo estaba regulado en el texto original de la Constitución de $1917^{3}$, y cómo se encuentra dicha rama del derecho constitucional un siglo después.

El Poder Legislativo ha cambiado substancialmente en estos cien años de vigencia de la Constitución, se pueden percibir avances y retrocesos. De lo cual referiré en este estudio.

La pregunta de investigación es ¿en qué medida ciertas regulaciones al Poder Legislativo mexicano han promovido u obstaculizado la democracia? Entendiendo por democracia el gobierno del pueblo y para beneficio del pueblo, en el que se presentan los elementos descritos por Dahl como los "criterios de gobierno democrático", a saber: Participación efectiva, igualdad de voto, comprensión ilustrada, control de la agenda e inclusión de los adultos; y que produce como dicho autor señala las consecuencias deseables:

1) Evita la tiranía;

2) promueve derechos esenciales;

3) libertad general;

4) autodeterminación;

5) autonomía moral;

6) desarrollo humano;

7) protección de intereses personales esenciales;

8) igualdad política; además la democracia moderna produce

9) búsqueda de la paz y

10) prosperidad. $^{4}$

México, D.F. UNAM, Instituto de Investigaciones Jurídicas, 2016, xvi, 359 páginas (Instituto de Investigaciones Jurídicas. Serie Doctrina Jurídica, 765). Disponible en: <https://biblio.juridicas.unam.mx/bjv/detalle-libro/4236-el-derecho-parlamentario-estatal-mexicano-analisis-y-propuesta-de-reforma>.

3 "Constitución Política de los Estados Unidos Mexicanos, Publicación Original: DOF 05-02-1917”, Página de internet de la Cámara de Diputados, disponible en: <http://www.diputados.gob.mx/LeyesBiblio/ref/cpeum/CPEUM_orig_ 05feb1917.pdf> (consultado mayo de 2019).

${ }^{4}$ Dahl, Robert A., La democracia: una guía para los ciudadanos, traducción de Fernando Vallespín, Madrid, Taurus, 1999, pp. 47-72. 
O como lo señala Jorge Carpizo "que "la democracia es el sistema en el cual los gobernantes son electos periódicamente por los electores; el poder se encuentra distribuido entre varios órganos con competencias propias y con equilibrios y controles entre ellos, así como responsabilidades señaladas en la Constitución con el objeto de asegurar los derechos fundamentales que la propia Constitución reconoce directa o indirectamente". ${ }^{5}$

Es decir, cuando hablo de democracia me refiero a distribución del poder, el equilibrio entre los órganos, el control de los mismos, la delimitación de competencias y la exigencia de responsabilidad de los funcionarios.

Al referirme a avances y retrocesos, en este artículo presentaré lo que de acuerdo con estas teorías de la democracia ha fortalecido esta, o bien, la ha debilitado.

Estos "avances" y "retrocesos" se han dado a través de procesos de reforma constitucional atendiendo a coyunturas políticas y situaciones concretas del momento, es decir, se realizaron para atender o resolver una situación específica que ameritaba un cambio en el texto constitucional. En su momento quizá el legislador consideró que la reforma constitucional ayudaba a la democracia, sin embargo, un análisis retrospectivo puede mostrar si fue así o no.

Con este estudio busco presentar al estudioso del Poder Legislativo y del sistema político mexicano una reflexión sobre la situación actual de la institución representativa y cómo podría mejorarse, para una mayor consolidación democrática. Asimismo, proporcionar elementos de análisis para una posible reforma constitucional del Congreso General y de las Legislaturas Estatales.

Además, este artículo puede ser útil también para comprender la

${ }^{5}$ Carpizo, Jorge, "Concepto de democracia y sistema de gobierno en América Latina", en Boletín Mexicano de Derecho Comparado, México, Instituto de Investigaciones Jurídicas, UNAM. Nueva serie, año XL, No 119, mayo-agosto, 2007, p. 357. 
historia constitucional de México a través de la evolución del parlamento. También puede coadyuvar a resolver problemas actuales de pesos y contrapesos en los poderes federales y estatales.

Actualmente existe el problema de la falta de confianza en el Poder Legislativo y la consecuente poca credibilidad a su actuación; en algunos casos, se le ve como una institución onerosa cuyos miembros solo buscan su propio interés y no el interés general; o bien, se concibe como un obstáculo para el desarrollo del país por su inactividad o incapacidad. ${ }^{6}$ Sin embargo, el Poder Legislativo es una institución fundamental para el equilibrio de poderes, y es menester estudiarlo para encontrar sus fortalezas y debilidades.

Planteo como objetivos de este trabajo: 1) realizar una reflexión histórico-comparada de los cambios al Congreso General de los Estados Unidos en este siglo de vigencia de la Constitución, para obtener conclusiones sobre la utilidad o no de los mismos, para la consolidación de la democracia; 2) proponer opciones de reformas constitucionales para fortalecer a la institución parlamentaria y mejorar su desarrollo; 3) identificar cambios constitucionales que no han sido de utilidad para la democracia y el equilibrio de poderes, y que necesitan ser discutidos.

El enfoque de este artículo es comparativo-reflexivo, confrontando el texto original de la Constitución y el texto actual. Primero, mencionaré la regulación del Poder Legislativo en 1917 comparando con la vigente a mayo de 2019; posteriormente, analizaré dichas

${ }^{6}$ Para ello, baste ver las encuestas de opinión pública acerca de la confianza de los ciudadanos en las instituciones políticas; en ellas aparecen siempre los diputados y senadores en los últimos lugares, al igual que la policía y los políticos, en general. Al respecto puede verse: Chávez Hernández, Efrén, "Ética en el Poder Legislativo", Boletín Mexicano de Derecho Comparado, México, Instituto de Investigaciones Jurídicas, UNAM, Nueva Serie, Año XXXIX, No. 115, enero-abril, 2006. (Disponible en: <https://revistas.juridicas.unam.mx/index.php/derecho-comparado/article/view/3869/4851>. 
diferencias señalando aspectos positivos y negativos respecto a la democracia y equilibrio de poderes. Finalmente, presentaré perspectivas del derecho parlamentario a un siglo de la vigencia de la constitución.

\section{El poder legislativo en EL teXto ORIGinal de LA CONS- TITUCIÓN DE 1917}

Uno de los mayores cambios del Poder Legislativo ha sido la composición de las cámaras. En efecto, la Cámara de Diputados se integraba por un número no definido de integrantes, sino elegida por una base poblacional: un diputado propietario por cada sesenta mil habitantes o por una fracción que pase de veinte mil, o por un Estado o Territorio que contare con menos de la población señalada (artículo 52); elegidos directamente por los ciudadanos cada dos años (artículo 51).

Así, la primera legislatura elegida de acuerdo a la nueva Constitución, la XXVII Legislatura de la Cámara de Diputados que inició el 15 de abril de 1917 y terminó el 31 de agosto de 1918, contó con 256 diputados ${ }^{7}$.

La Cámara de Senadores, por su parte, estaba integrada por dos senadores por cada Estado y el entonces Distrito Federal (hoy Ciudad de México) en elección directa; cada senador duraba cuatro

7 Esto de acuerdo con el conteo realizado por Luis Godoy, quien también afirma que la siguiente legislatura (diciembre de 1918 a agosto de 1920) tuvo 253 diputados. Godoy, Luis, Reelección en la Cámara de Diputados, 1917-1934; Federalismo y ambición política Tesis para obtener el título de la licenciatura en Ciencia Política, México, Instituto Tecnológico Autónomo de México, sin año, p. 23, disponible en: <http://departamentodecienciapolitica.itam.mx/sites/default/files/u327/ tesis_luis_godoy.pdf $>$ (consultado noviembre de 2016). También puede consultarse: LEGISLATURAS XXVII-LX (1917-2009); Diputados Integrantes, México, Cámara de Diputados del H. Congreso de la Unión, LX Legislatura, 2008, disponible en: <http://www.diputados.gob.mx/sedia/biblio/virtual/dip/leg27-60.htm (consultado noviembre de 2016)>. 
años en su cargo, pero la cámara se renovaba por mitad cada dos años (artículos 56 y 58).

Así, de acuerdo con el artículo 43 que enumeraba los 28 Estados integrantes de la Federación, el Distrito Federal y los territorios de la Baja California y de Quintana Roo, la primera legislatura elegida de acuerdo a esta Constitución tuvo 58 senadores.

Actualmente, la Cámara de Diputados se compone por 500 miembros: 300 de mayoría relativa y 200 de representación proporcional, elegidos cada tres años. Mientras que la Cámara de Senadores se integra por 128 miembros: 2 de mayoría por cada Estado y la Ciudad de México, 1 de primera minoría; y 32 de representación proporcional; se renueva totalmente cada seis años.

La edad establecida en 1917 para ser elegido diputado era de 25 años, mientras que para senador era 35 (artículos 55 y 59). No había ninguna limitación para la relección de los diputados y senadores. En 2019, las edades determinadas son de 21 y 25 años, respectivamente; con posibilidad de relección hasta por cuatro periodos consecutivos para diputados, y hasta por dos periodos consecutivos para senadores.

En el texto original, se facultó a la propia Cámara de Diputados y de Senadores para calificar de las elecciones de sus miembros (artículo 60); al presente, lo realiza el Instituto Nacional Electoral.

Para sesionar, el texto original de la Constitución de 1917 exigía la presencia de las dos terceras partes de los miembros en la Cámara de Senadores y de más de la mitad del número total de los miembros de la Cámara de Diputados (artículo 63). Hoy se requiere solo más de la mitad de sus miembros en ambas cámaras.

En el texto original de la Constitución se regulaba únicamente un periodo ordinario de sesiones, que iniciaba el primero de septiembre y concluía a más tardar el 31 de diciembre (artículos 65 y 66), además, sólo el Presidente de la República podía convocar a sesiones 
extraordinarias (artículo 67). En la actualidad, son dos periodos de sesiones: del 1 de septiembre al 15 de diciembre, y del 1 de febrero al 30 de abril; y es la Comisión Permanente quien tiene ahora la facultad de convocar a sesiones extraordinarias del Congreso.

En 1917 se ordenó que a la apertura de las sesiones ordinarias asistiera el Presidente de la República para presentar un informe por escrito sobre el estado general de la administración pública del país; y en el caso de sesiones extraordinarias, para informar las razones de la convocatoria (artículo 69). Ahora, ya no asiste el Presidente de la República al Congreso, solo envía el informe por escrito; y en el segundo periodo de sesiones, envía a la Cámara de Senadores la Estrategia Nacional de Seguridad Pública para su aprobación.

Con motivo de dicha reforma que retiró la obligación del presidente para asistir al Congreso a presentar su informe, se introdujo la llamada "pregunta parlamentaria", que se realiza por escrito dirigido al Presidente de la República y/o a los titulares de las dependencias y entidades del gobierno federal, solicitándoles mayor información o documentación (artículos 69 y 93).

Otro aspecto interesante es que el texto original facultaba al Congreso en la fracción XXIII del artículo 73 "para formar su reglamento interior"; posteriormente, en el año 1977 se agregó en el artículo 70 la posibilidad explícita del Congreso para expedir la Ley que regulara su estructura y funcionamiento internos, sin la intervención del Poder Ejecutivo. Es decir, que la facultad reglamentaria del Congreso fue desarrollándose con el tiempo.

En 1917, el texto de la constitución hacía referencia al "Reglamento de Debates" para regular sobre la forma, intervalos y modo de proceder en las discusiones y votaciones (artículo 72); en la actualidad, el texto refiere a la "Ley del Congreso y sus reglamentos 
respectivos". 8

Referente al proceso legislativo, en el texto original de la constitución no concedía a los ciudadanos la facultad de iniciar leyes o decretos ante el Congreso; fue en el año 2012 cuando se incluyó dicha prerrogativa a los ciudadanos en un número equivalente, por lo menos, al cero punto trece por ciento de la lista nominal de electores (artículo 71 fracción IV). Asimismo, en dicho año se incluyó la "iniciativa preferente" para el Presidente de la República, mediante la cual dicho funcionario puede presentar hasta dos iniciativas que deberán discutirse por el pleno de la cámara respectiva en un máximo de treinta días naturales.

Respecto a la distribución de competencias entre los órganos federales y estatales, el artículo 73 constitucional (el más reformado de todos) referido a las facultades del Congreso General en 1917 contaba con 31 fracciones (I a XXXI); en mayo de 2019, contaba con 54 fracciones vigentes ${ }^{9}$, es decir, durante estos 100 años se añadieron en promedio 20 fracciones, lo que implicó un aumento de $62 \%$ de las facultades federales.

${ }^{8}$ Son la "Ley Orgánica del Congreso General de los Estados Unidos Mexicanos", publicada en el Diario Oficial de la Federación el 03-09-1999; el "Reglamento para el Gobierno Interior del Congreso General de los Estados Unidos Mexicanos" de 20-03-1934; el "Reglamento del Senado de la República" del 0406-2010; así como el "Reglamento de la Cámara de Diputados" de 24-12-2010.

${ }^{9}$ Son las siguientes fracciones: I, III, V, VII, VIII, IX, X, XI, XII, XIII, XIV, XV, XVI, XVII, XVIII, XIX, XX, XXI, XXII, XXIII, XXIV, XXV, XXVI, XXVII, XXVIII, XXIX, XXIX-B, XXIX-C, XXIX-D, XXIX-E, XXIX-F, XXIX-G, XXIX-H, XXIX-I, XXIX-J, XXIX-K, XXIX-L, XXIX-M, XXIX-N, XXIX-Ñ, XXIX-O, XXIX-P, XXIX-Q, XXIX-R, XXIX-S, XXIX-T, XXIX-U, XXIX-V, XXIX-W, XXIX-X, XXIX-Y, XXIX-Z, XXX y XXXI. Al respecto puede consultarse la versión actualizada de la Constitución. "CONSTITUCIÓN POLÍTICA DE LOS ESTADOS UNIDOS MEXICANOS; Constitución publicada en el Diario Oficial de la Federación el 5 de febrero de 1917. Texto vigente; Última reforma publicada DOF 15-05-2019”, Página de Internet de la Cámara de Diputados, <http://www.diputados.gob.mx/LeyesBiblio/ref/cpeum.htm> (consultado mayo de 2019). 
Por su parte, el artículo 74 que se refiere a las facultades exclusivas de la Cámara de Diputados pasó de 6 a 9 fracciones de 1917 a 2019, es decir, aumentó 50\%.

El artículo 76 referido a las facultades exclusivas de la Cámara de Senadores, aumentó de 8 a 13 fracciones vigentes (son XIV, pero la fracción IX está derogada), creciendo un 62.5\%.

Otro aspecto relevante de cambio es la composición de la Comisión Permanente: en el artículo 78 del texto original se estableció que la formarían 29 miembros: 15 diputados y 14 senadores; actualmente son 37 miembros, de ellos 19 diputados y 18 senadores.

El artículo 79 del texto original refería las facultades de la Comisión Permanente, ahora están en el 78; dichas facultades han pasado de ser IV fracciones en 1917 a VII fracciones vigentes (son ocho fracciones pero la $\mathrm{V}$ está derogada).

Referente a la entidad encargada de la fiscalización de las cuentas públicas, en 1917 se contemplaba a la Contaduría Mayor, facultando al Congreso a expedir la Ley Orgánica de dicha entidad (artículo 73, fracción XXIV) y a la Cámara de Diputados a vigilar su desempeño a través de una Comisión (artículo 74 fracción II). En la actualidad, está regulada en el artículo 79 la Auditoría Superior de la Federación de la Cámara de Diputados, como entidad encargada de la fiscalización.

Una facultad que tenía el Congreso en el texto original era autorizar al Presidente de la República para poder ausentarse del territorio nacional, ya que, de acuerdo con el artículo 88, el presidente no podía salir sin ese permiso. Sin embargo, dicho precepto fue reformado en 1966 y 2008 para eliminar tal facultad del Congreso, y establecer que el presidente puede ausentarse hasta siete días con solo informar los motivos a la Cámara de Senadores o a la Comisión Permanente, y en periodos mayores a ese término, pedirá el permiso solo a la Cámara de Senadores. 
También era una facultad del Congreso de la Unión la elección de los miembros de la Suprema Corte de Justicia de la Nación mediante Colegio Electoral que reunía a cuando menos dos terceras partes del número total de diputados y senadores. Así, el Congreso elegía por escrutinio secreto y mayoría absoluta de votos, de entre los candidatos propuestos por los Congresos Estatales (artículo 96). Actualmente, se le ha quitado también tal facultad al Congreso y se le ha entregado sólo a la Cámara de Senadores, pasando al Presidente de la República la potestad de proponer los candidatos.

Como se puede observar, han sido muchos aspectos los que ha cambiado la regulación del Poder Legislativo, algunos positivos y otros negativos, avances y retrocesos en este camino hacia la democracia, como señalaré en el siguiente apartado.

A continuación presento este cuadro resumen:

\section{PRINCIPALES ASPECTOS DEL PODER LEGISLATIVO EN EL TEX- TO ORIGINAL DE LA CONSTITUCIÓN Y EN LA ACTUALIDAD}

\begin{tabular}{|c|c|c|}
\hline & Texto original 1917 & Texto actual (mayo de 2019) \\
\hline $\begin{array}{l}\text { Composición } \\
\text { Cámara de } \\
\text { Diputados }\end{array}$ & $\begin{array}{l}\text { Número indefinido, un } \\
\text { diputado por cada } 60,000 \\
\text { habitantes y fracción de } \\
20,000 \\
\text { (256 diputados elegidos en } \\
1917 \text { ) } \\
2 \text { años de duración }\end{array}$ & $\begin{array}{l}500 \text { diputados: } 300 \text { de } \\
\text { mayoría relativa y } 200 \text { de } \\
\text { representación proporcional }\end{array}$ \\
\hline $\begin{array}{l}\text { Composición } \\
\text { Cámara de } \\
\text { Senadores }\end{array}$ & $\begin{array}{l}\text { Dos senadores por cada } \\
\text { Estado y el Distrito Federal } \\
\text { (58 senadores elegidos en } \\
1917) \\
4 \text { años de duración } \\
\text { La cámara se renovaba cada } \\
\text { cuatro años }\end{array}$ & $\begin{array}{l}128 \text { miembros ( } 2 \\
\text { por cada Estado y la } \\
\text { Ciudad de México, } 1 \\
\text { de primera minoría; } \\
32 \text { de representación } \\
\text { proporcional). }\end{array}$ \\
\hline $\begin{array}{l}\text { Edad para ser } \\
\text { diputado }\end{array}$ & 25 años & 21 años \\
\hline
\end{tabular}




\begin{tabular}{|c|c|c|}
\hline $\begin{array}{l}\text { Edad para ser } \\
\text { senador }\end{array}$ & 35 años & 25 años \\
\hline $\begin{array}{l}\text { Limitación para } \\
\text { elección consecutiva } \\
\text { (reelección) }\end{array}$ & $\begin{array}{l}\text { Ninguna para ambas } \\
\text { cámaras }\end{array}$ & $\begin{array}{l}\text { Los Senadores podrán } \\
\text { ser electos hasta por dos } \\
\text { periodos consecutivos y los } \\
\text { Diputados al Congreso de } \\
\text { la Unión hasta por cuatro } \\
\text { periodos consecutivos }\end{array}$ \\
\hline $\begin{array}{l}\text { Calificación de } \\
\text { la elección de las } \\
\text { cámaras }\end{array}$ & $\begin{array}{l}\text { Autocalificación (cada una } \\
\text { de las cámaras) }\end{array}$ & Instituto Nacional Electoral \\
\hline $\begin{array}{l}\text { Quórum mínimo } \\
\text { para sesionar las } \\
\text { cámaras }\end{array}$ & $\begin{array}{l}\text { Dos terceras partes de los } \\
\text { miembros en la Cámara de } \\
\text { Senadores; más de la mitad } \\
\text { en la Cámara de Diputados }\end{array}$ & $\begin{array}{l}\text { Más de la mitad de sus } \\
\text { miembros en ambas } \\
\text { cámaras }\end{array}$ \\
\hline $\begin{array}{l}\text { Periodos ordinarios } \\
\text { de sesiones }\end{array}$ & $\begin{array}{l}\text { Uno: del } 1 \text { de septiembre al } \\
31 \text { de diciembre }\end{array}$ & $\begin{array}{l}\text { Dos: Del } 1 \text { de septiembre al } \\
15 \text { de diciembre; y del } 1 \text { de } \\
\text { febrero al } 30 \text { de abril. }\end{array}$ \\
\hline $\begin{array}{l}\text { Facultado para } \\
\text { convocar a sesiones } \\
\text { extraordinarias }\end{array}$ & Presidente de la República & Comisión Permanente \\
\hline $\begin{array}{l}\text { Informe del } \\
\text { Presidente de la } \\
\text { República }\end{array}$ & $\begin{array}{l}\text { Asistía y presentaba un } \\
\text { informe por escrito }\end{array}$ & $\begin{array}{l}\text { No asiste, solo envía } \\
\text { informe por escrito }\end{array}$ \\
\hline $\begin{array}{l}\text { Pregunta } \\
\text { parlamentaria }\end{array}$ & No regulada & $\begin{array}{l}\text { Por escrito a Presidente } \\
\text { de la República y titulares } \\
\text { de las dependencias y } \\
\text { entidades del gobierno } \\
\text { federal }\end{array}$ \\
\hline $\begin{array}{l}\text { Facultad de } \\
\text { iniciativa legislativa a } \\
\text { ciudadanos }\end{array}$ & No & $\begin{array}{l}\text { Sí, a un número equivalente } \\
\text { al } 0.13 \% \text { de la lista nominal } \\
\text { de electores }\end{array}$ \\
\hline $\begin{array}{l}\text { Iniciativa preferente } \\
\text { del Presidente de la } \\
\text { República }\end{array}$ & No regulada & $\begin{array}{l}\text { Hasta } 2 \text { en el inicio de } \\
\text { cada periodo ordinario de } \\
\text { sesiones }\end{array}$ \\
\hline
\end{tabular}




\begin{tabular}{|c|c|c|}
\hline $\begin{array}{l}\text { Norma que regula el } \\
\text { proceso legislativo }\end{array}$ & Reglamento de Debates & $\begin{array}{l}\text { Ley y Reglamento del } \\
\text { Congreso; y reglamentos de } \\
\text { cada cámara }\end{array}$ \\
\hline $\begin{array}{l}\text { Fracciones vigentes } \\
\text { del artículo } 73 \\
\text { constitucional }\end{array}$ & 31 & 54 \\
\hline $\begin{array}{l}\text { Fracciones vigentes } \\
\text { del artículo } 74 \\
\text { constitucional }\end{array}$ & 6 & 9 \\
\hline $\begin{array}{l}\text { Fracciones vigentes } \\
\text { del artículo } 76 \\
\text { constitucional }\end{array}$ & 8 & 13 \\
\hline $\begin{array}{l}\text { Composición } \\
\text { de la Comisión } \\
\text { Permanente }\end{array}$ & $\begin{array}{l}29 \text { miembros: } 15 \text { diputados } \\
\text { y } 14 \text { senadores }\end{array}$ & $\begin{array}{l}37 \text { miembros: } 19 \text { diputados } \\
\text { y } 18 \text { senadores }\end{array}$ \\
\hline $\begin{array}{l}\text { Entidad encargada } \\
\text { de la fiscalización }\end{array}$ & Contaduría Mayor & $\begin{array}{l}\text { Auditoría Superior de la } \\
\text { Federación de la Cámara de } \\
\text { Diputados }\end{array}$ \\
\hline $\begin{array}{l}\text { Facultad para } \\
\text { autorizar las } \\
\text { ausencias del } \\
\text { territorio nacional } \\
\text { del Presidente de la } \\
\text { República }\end{array}$ & $\begin{array}{l}\text { Sí, del Congreso en todos } \\
\text { los casos }\end{array}$ & $\begin{array}{l}\text { No. Sólo en periodos } \\
\text { mayores a } 7 \text { días, debe } \\
\text { autorizar el Senado. }\end{array}$ \\
\hline $\begin{array}{l}\text { Facultad para elegir } \\
\text { los miembros de la } \\
\text { Suprema Corte de } \\
\text { Justicia }\end{array}$ & $\begin{array}{l}\text { Congreso de la Unión } \\
\text { en Colegio Electoral; } \\
\text { candidatos propuestos por } \\
\text { cada Legislatura de los } \\
\text { Estados }\end{array}$ & $\begin{array}{l}\text { Cámara de Senadores, a } \\
\text { propuesta de terna enviada } \\
\text { por Presidente de la } \\
\text { República }\end{array}$ \\
\hline
\end{tabular}

Fuente: Elaboración propia.

\section{Cien años de cambios en el derecho parlamentario MEXICANO}

A cien años de vigencia de la Constitución de 1917, se puede cuestionar qué tanto ha cambiado el Poder Legislativo y, por consiguiente, la rama que lo estudia: el derecho parlamentario. 
Para empezar, en 1917 no se hablaba de derecho parlamentario como disciplina jurídica que estudiara al Poder Legislativo, sino como simple recopilación de normas relativas a dicho órgano. Así está la obra de Jeremy Bentham intitulada "Tácticas parlamentarias" 10 de 1791 y la obra de Tomás Jefferson, quien escribió en 1801 el "Manual del Derecho Parlamentario ó Resumen de las reglas que se observan en el parlamento de Inglaterra y en el Congreso de los Estados Unidos para la proposición, discusión y decisión de los negocios" ". Sin embargo, como lo señala Garronera, no es sino hasta las obras de Vincenzo Miceli ("Principii de diritto parlamentare", 1910), Hatschek ("Das Parlamentsrecht des Dent", 1915), Federico Mohrhoff ("Trattato di Diritto e procedure parlamentare", 1948) o Marcel Prélot ("Droit parlementaire français", 1957-58) donde se encontrarán auténticas obras doctrinarias de conjunto acerca del derecho parlamentario. ${ }^{12}$

En México, no se hablaba tampoco de derecho parlamentario sino hasta la obra de Quiroga Lavié en 1987, ${ }^{13}$ antes, en 1973 Ochoa Campos usó el término "derecho legislativo" para referirse

${ }^{10}$ El título completo era: "Un ensayo sobre tácticas políticas, o investigaciones relativas a la disciplina y el modo apropiado de proceder que deben observarse en las asambleas políticas: principalmente aplicados a la práctica del Parlamento británico, y para la constitución y situación de la Asamblea Nacional de Francia", aunque ha sido traducido simplemente como "Tácticas parlamentarias", existen diversas ediciones, por ejemplo: Bentham, Jeremy, Tácticas parlamentarias, prólogo de Gustavo Carvajal Moreno, México, Coordinación de los Diputados del Sector Popular del Partido Revolucionario Institucional, 2002.

${ }^{11}$ Existen ediciones en castellano, por ejemplo: Jefferson, Tomás, Manual del Derecho Parlamentario ó Resumen de las Reglas, prólogo de Augusto Gómez Villanueva, traducido por Joaquín Ortega, México, Talleres de Reproducciones OSVIC, 2002 [Edición facsimilar de la obra de 1827].

${ }^{12}$ Garrorena Morales, A., "Parlamento", en Aragón Reyes, Manuel, Temas básicos de derecho constitucional; Tomo II: Organización del Estado, Madrid, España, Civitas, 2001, p. 78-79.

${ }^{13}$ Quiroga Lavié, Humberto et al., Derecho parlamentario iberoamericano, México, 
a esta disciplina. ${ }^{14}$

Por tanto, uno de los avances en estos primeros cien años de la Constitución, es que se ha desarrollado y consolidado el derecho parlamentario en México, como disciplina estudiosa del Poder Legislativo.

Respecto a la regulación del Poder Legislativo en el texto constitucional, también existe un crecimiento considerable. Los artículos referidos específicamente al Poder Legislativo en la Constitución de 1917, se encuentran en el Título Tercero, capítulo segundo, del artículo 50 al 79. Son treinta artículos que han sufrido en total 212 reformas, lo que implica un promedio de 7.06 cambios por artículo, aunque como se puede ver en el siguiente cuadro hay artículos que no han sufrido modificación alguna, y otros que han sido reformados en más de 80 veces. ${ }^{15}$

El artículo más reformado ha sido el 73, con 82 modificaciones (hasta mayo de 2019); mientras que los artículos 50, 57, 64 y 68 no han tenido cambios. El texto de dichos artículos ha pasado de un aproximado de 4,629 a 11,402 palabras, creciendo 2.4 veces el número de vocablos.

Esto muestra que la importancia del Poder Legislativo en México ha aumentado, a tal grado de ampliar sus funciones y la extensión de su regulación.

Porrúa, Instituto de investigaciones legislativas, 1987, p. 245.

${ }^{14}$ Ochoa Campos, Moisés (dir.), Derecho Legislativo Mexicano, dirigido y escrito en parte por Moisés Ochoa Campos, con la colaboración de Jorge Carpizo, Héctor Manuel Ezeta, Jorge Sayeg Helú y otros, México, XLVIII Legislatura del Congreso de la Unión, Cámara de Diputados, 1973, p. 381.

${ }^{15} \mathrm{Al}$ respecto, puede verse el detalle de todas las reformas constitucionales a estos artículos en: México. Cámara de Diputados, "Reformas Constitucionales por Artículo; Última reforma publicada en el Diario Oficial de la Federación el 15 de mayo de 2019", Página de internet de la Cámara de Diputados, http://www. diputados.gob.mx/LeyesBiblio/ref/cpeum_art.htm (consultado mayo de 2019). 
Sin embargo, se puede analizar si estos cambios han sido benéficos para un mejor desarrollo de sus funciones, o bien, ha afectado el equilibrio de poderes y/o el sistema federal.

Como lo han señalado diversos autores en diversos foros ${ }^{16}$, se puede considerar como positivo para mejorar el proceso legislativo las reformas constitucionales que se realizaron para aumentaron los periodos de sesiones ordinarios; para modificar el quórum mínimo requerido para sesionar las cámaras, para hacer más fácil su funcionamiento; también, la facultad que se le retiró al Presidente de la República para convocar a sesiones extraordinarias; las normas que establecieron para regular con mayor detalle el proceso legislativo; la facultad de iniciativa legislativa concedida a los ciudadanos y la iniciativa preferente del Presidente de la República.

De igual forma, las reformas sobre la composición de la Cámara de Diputados; la disminución de la edad para ser diputado; y la calificación de la elección de las cámaras, a cargo de un órgano autónomo distinto, han ayudado a la consolidación de la democracia porque acercan más a los objetivos deseables señalados por Dahl y referidos previamente.

La reforma sobre la composición de la Comisión Permanente y su facultad para convocar a sesiones extraordinarias; el establecimiento de la pregunta parlamentaria; así como el diseño de una nueva entidad encargada de la fiscalización, han favorecidola con-

${ }^{16}$ Por ejemplo, las recopiladas en la obras: Reformas urgentes al marco jurídico del Congreso mexicano, 2a. ed., México, Cámara de Diputados, LIX Legislatura, Comisión de Reglamentos y Prácticas Parlamentarias, 2006, 2 ts; El Poder Legislativo federal y local en el marco de un nuevo federalismo. Encuentro Nacional de Comisiones de Reglamentos y Prácticas Parlamentarias u Homólogas, 18 de febrero de 2005, Colima, México, Cámara de Diputados, Comisión de Reglamentos y Prácticas Parlamentarias, 2005; Reforma y modernización del Poder Legislativo federal y local. Segundo Encuentro $\mathrm{Na}$ cional de Comisiones de Reglamentos y Prácticas Parlamentarias u Homólogas, 23 de septiembre de 2005, La Paz, Baja California Sur, México, Cámara de Diputados, Comisión de Reglamentos y Prácticas Parlamentarias, 2006. 
solidación del Poder Legislativo como institución autónoma, en mayor equilibrio frente al Poder Ejecutivo.

No obstante, pueden ser dañinas para el fortalecimiento del Poder Legislativo y del federalismo: las reformas sobre la composición de la Cámara de Senadores; la edad para ser senador; el aumento de la duración del encargo de diputados y senadores; la limitación para reelección consecutiva (que aunque ya no se prohíbe absolutamente, dista de ser como en el texto original); la regulación actual del informe del Presidente de la República; la eliminación de la facultad del Congreso para autorizar las ausencias del territorio nacional del Presidente de la República; y la supresión de la participación de la Cámara de Diputados y las Legislaturas de los Estados en la elección de los miembros de la Suprema Corte de Justicia.

En efecto, se puede apreciar que las múltiples reformas constitucionales, especialmente la de 1996 que modificó la composición de la Cámara de Senadores, han transformado dicho órgano, de una cámara de representación territorial garante del federalismo, a una cámara estamental representante de las élites partidistas. ${ }^{17}$

El Senado ha perdido la vinculación con las Entidades Federativas, ya que rompió con el equilibrio de dos senadores por cada Estado y el Distrito Federal (hoy Ciudad de México); además, se eliminó la facultad de las Legislaturas estatales para declarar electo al senador respectivo.

De igual forma, la reforma que disminuyó la edad para ser senador le ha quitado también el carácter de ser "cámara de personas sabias por la edad", necesaria para ser contrapeso de la otra cámara.

17 Basta observar a los senadores de representación proporcional, quienes en su mayoría son colocados por decisión de las presidencias de los partidos políticos nacionales, generalmente sin pasar por un proceso democrático de elección interna; y una vez electos, ejercen los principales cargos directivos de la Cámara, de las comisiones y grupos. 
Y aumentar de cuatro a seis años la duración en el encargo de los senadores ha aumentado el poder de sus miembros, ya que no se tienen que someter a escrutinio público en un periodo muy largo. De igual forma, al eliminar la renovación por mitad de la cámara cada dos años, se les quita a los ciudadanos la posibilidad de confirmar o remover a sus representantes en un periodo de tiempo menor.

Por lo anterior, sugiero volver al esquema original del Senado: dos senadores elegidos por elección directa en cada Entidad Federativa por un encargo de cuatro años; renovable la cámara por mitad cada dos años, y que sea la Legislatura estatal quien declare electo al senador respectivo, debiendo además rendir protesta ante dicho órgano. Además, si se elimina toda restricción de relección, se fomentará que el representante popular se comprometa con la ciudadanía y que estos premien con su voto al buen legislador, y castiguen al mal representante.

Así se consolidará la representación de los Estados y el federalismo. La experiencia de los Estados Unidos de América muestra que sí ha funcionado este diseño. ${ }^{18}$

Referente a la duración del encargo de diputados y la limitación para reelección consecutiva, también ayudaría a la democracia el volver al diseño original de dos años, sin limitación de relección. Así, los diputados se someterían cada dos años a examen de la ciudadanía, y estos podrán confirmar a quienes han realizado un buen trabajo. ${ }^{19}$

${ }^{18}$ Puede verse: Chávez Hernández, Efrén, “¿El federalismo ayuda a combatir el autoritarismo? Un análisis comparado entre el diseño constitucional de Estados Unidos y México", CIfUREP. Textos furídicos y Políticos, Tlaxcala, México, Año 6, núm. 7, enero-junio 2018, Universidad Autónoma de Tlaxcala, ISSN 2395-9460, pp. 43-76. Disponible en: <http://garantismoyderechoshumanos.com.mx/Articulos/cargaArticulo/17-P>.

${ }^{19}$ Respecto a los diputados de representación proporcional, en otro trabajo propongo la modificación en la asignación de los mismos: no mediante listas ce- 
Sobre el informe presidencial, se puede apreciar claramente que la reforma constitucional que suprimió la obligación del Presidente de la República para acudir al Congreso quitó una herramienta importante de control parlamentario para el equilibrio de poderes. En efecto, el acudir al Congreso representaba una oportunidad de diálogo de poderes y de rendición de cuentas ante el pueblo representado por el Congreso. Si bien, la redacción original de la constitución solo indicaba de acudir y presentar un informe por escrito, la democratización del sistema político implicaba que se avanzara hacia lograr un diálogo efectivo entre los poderes, y que el Ejecutivo escuchara los posicionamientos de los grupos parlamentarios.

Por el contrario, la reforma constitucional de 2008 fue favorable al Presidente de la República, quien ahora ya no se somete al examen de su gestión ante el Congreso, y por el contrario, ahora es un monólogo, pues el Ejecutivo puede organizar un foro aparte donde nadie lo cuestione ni analice objetivamente el estado que guarda la administración pública del país, tarea que debía realizar el Congreso.

Por lo anterior, propongo que se vuelva al anterior esquema de asistencia al congreso, y no solo presente un informe por escrito, sino que también escuche a los representantes populares y responda a sus cuestionamientos, como ocurre en los sistemas democráticos. ${ }^{20}$

rradas presentadas por los partidos políticos, sino por listas formadas con los candidatos no ganadores que hayan obtenido la mayor votación, de mayor a menor. Se puede ver: Chávez Hernández, Efrén, El derecho parlamentario estatal mexicano. op. cit., pp. 177-179.

20 Sobre el informe presidencial y las propuestas de modificación al informe, puede verse: Chávez Hernández, Efrén, "Algunas propuestas de modificación al formato del informe presidencial en México", en Boletín Mexicano de Derecho Comparado, México, Instituto de Investigaciones Jurídicas, UNAM. Nueva Serie, Año XXXV, No. 105, Septiembre-Diciembre, 2002. Disponible en: <https://revistas. juridicas.unam.mx/index.php/derecho-comparado/article/view/3733/4599 >. 
Otra facultad que perdió el Congreso en conjunto, y que la regulación actual favorece al Poder Ejecutivo federal, es la autorización que éste debía dar para que el Presidente de la República pudiera ausentarse del territorio nacional. Ahora solo comunica, y solo en las ausencias mayores de siete días solicita permiso a la Cámara de Senadores.

Esta facultad para otorgar permiso al Presidente de la República era también un acto de control que ejercía el Congreso, y que permitía un mayor diálogo y colaboración. Con todo, el constituyente permanente decidió quitar esa facultad al Congreso, favoreciendo nuevamente al Poder Ejecutivo en detrimento de un equilibrio de poderes.

Recuérdese que la tarea principal del Congreso es controlar al Ejecutivo, para mantener los pesos y contrapesos que requieren los poderes públicos en un Estado democrático de Derecho, evitándose los abusos de poder.

Esta era una herramienta importante, especialmente para la oposición, para controlar al Presidente de la República. Por ello, sugiero se restablezca como lo señalaba el texto original de la constitución.

Finalmente, tocante a la facultad para nombrar a los miembros de la Suprema Corte de Justicia que el Congreso tenía a propuesta de las Legislaturas estatales, la original regulación favorecía el sistema federal y la participación de las Legislaturas estatales y de todo el Congreso.

Efectivamente, ahora solo participa el Senado, y se le ha otorgado al Presidente de la República el monopolio en la proposición de candidatos al máximo tribunal del país, concentrando más poder en él y restando facultades al Congreso.

Además, actualmente las Legislaturas de los Estados han perdido toda participación en la integración de este importantísimo tribunal; pues como lo señalé, el Senado ya no representa a las Entidades Federativas, no solo porque se ha desvirtuado en su composición, 
sino porque los senadores no tienen una vinculación directa con la Legislatura del Estado como sí ocurría en el texto original de 1917.

La Suprema Corte de Justicia de la Nación cuenta con facultades importantes que llevan a invalidar en muchos casos los actos de los congresos estatales, constituyéndose así dicho tribunal como un "superpoder", sin que exista un efectivo contrapeso.

Ante ello, propongo que se retorne al sistema establecido en el texto original, para que el nombramiento de los ministros de la Suprema Corte de Justicia sea mediante un proceso más democrático, el cual garantice que los jueces del máximo tribunal de México sean los mejores juristas de México, con el mayor sentido de compromiso y ética, capaces de velar por el respeto a las leyes y al bien común de toda la Nación.

En esto pueden participar los miembros del Poder Legislativo, tanto de la Cámara de Diputados, como de los congresos estatales.

iv. Perspectivas

Analizar el derecho parlamentario mexicano en un siglo de existencia de la Constitución de 1917, es una oportunidad para evaluar lo avanzado y proyectar hacia donde se podría progresar.

Sin duda, las condiciones de México en 1917 y en 2019 son distintas, por ejemplo, la población de México en 1917 era de aproximadamente 15 millones de habitantes ${ }^{21}$ y actualmente somos más de 110 millones de habitantes (112,336,538 de personas según el censo de 2010), pero se puede proyectar el México que los ciudadanos deseamos y cómo las instituciones deben colaborar.

21 De acuerdo con el Censo de Población, la población en 1910 era de 15,160,369. "Tercer Censo de Población de los Estados Unidos Mexicanos 1910", Página de internet del Instituto Nacional de Estadística y Geografía (INEGI), <http://www.inegi.org.mx/est/contenidos/proyectos/ccpv/cpv1910/> (consultado noviembre de 2016). 
Uno de los rubros necesarios, señalado reiteradamente en los foros referidos, es fortalecer el federalismo y el Estado de Derecho, esto se puede lograr buscando equilibrios efectivos entre los poderes. Es sumamente dañino la concentración de poder, en cualquiera de los entes o sujetos.

Por ello, es necesario que las legislaturas estatales participen con mayor peso en las decisiones nacionales, pues actualmente se les ha relegado al papel de ser replicadoras de la legislación federal.

Para lograr un mayor equilibrio de poderes, las legislaturas estatales deben tener una mayor injerencia en el proceso de reforma constitucional, por ejemplo, establecer que las modificaciones a la Constitución deban aprobarse por 2/3 o 3/4 partes de los congresos estatales, y no la simple mayoría como actualmente está regulado.

En los Estados Unidos de América una reforma constitucional requiere la ratificación de $3 / 4$ partes de las legislaturas de los Estados (artículo cinco de la Constitución de Estados Unidos). ${ }^{22}$ Y en Canadá, se necesita para una modificación constitucional la aprobación de 2/3 del total de las legislaturas de las provincias, que representen al menos el 50\% de la población de todas las provincias (artículo 38 (1) (b) de la Constitución de Canadá) y en ciertos asuntos, se pide la aprobación de todas las legislaturas provinciales (artículo 40)..$^{23}$

Por otra parte, en el ámbito de competencias, la Cámara de Senadores ha adquirido mayores prerrogativas, es decir, hay una ten-

${ }^{22}$ Puede consultarse dicho documento en idioma castellano: "La Constitución de los Estados Unidos de América 1787”, Página de Internet de National Archives, <https://www.archives.gov/espanol/constitucion.html> (consultado noviembre de 2016).

23 "Constitution Act, 1982", en A consolidation of the Constitution Acts 1867 to 1982, Ontario, Canada, Minister of Public Works and Government Services, 2012, pp. 65-66. Disponible en: <http://laws-lois.justice.gc.ca/PDF/CONST_E. pdf $>$ (consultado noviembre de 2016). 
dencia a reducir facultades del Congreso y concentrarlas solo en el Senado: autorizaciones al Ejecutivo, nombramiento de funcionarios, resolución de conflictos territoriales entre los Estados, por citar algunos ejemplos. En este asunto considero que no debe mermarse las competencias de la Cámara de Diputados, pues es modificar el equilibrio entre los poderes.

Las facultades y competencias distribuidas entre los poderes tienen como objetivo mantener la armonía de pesos y contrapesos. Basta ver la experiencia de países democráticos como Estados Unidos. En efecto, Woodrow Wilson cuando hacía referencia al equilibrio entre el gobierno nacional y los gobiernos de Estados en el sistema federal, citaba las palabras de John Adams sobre el sistema de balanzas (pesos y contrapesos) contenido en la Constitución: 1) los Estados y territorios contrapesan al gobierno nacional; 2) la Cámara de Representantes contrapesa al Senado, y viceversa; 3) la autoridad ejecutiva se contrapone en cierta forma a la autoridad legislativa; 4) el Poder Judicial contrapesa a la cámara de Representantes, al Senado, al Ejecutivo y a los gobiernos de los Estados; 5) el Senado contrapesa al Ejecutivo en todos los nombramientos de los funcionarios y en los Tratados Internacionales; 6) el pueblo tiene en la balanza a sus representantes a través de elecciones bienales; 7) las legislaturas de los Estados contrapesan al Senado por las elecciones sexenales; 8) los electores secundarios contrapesan al pueblo en la elección del presidente. ${ }^{24}$

En México, no operan igual estos pesos y contrapesos, sin duda, por la deformación del sistema federal que ha llevado incluso al autoritarismo en algunas épocas de la historia. ${ }^{25}$

${ }^{24}$ Wilson, Woodrow, El Gobierno Congresional. Régimen político de los Estados Unidos, México, Universidad Nacional Autónoma de México, 2002, pp. 9-10.

${ }^{25}$ Para profundizar en este tema puede consultarse: Chávez Hernández, Efrén, 
Evidentemente el Poder Legislativo ha mejorado en este siglo de vigencia de la Constitución, pero no lo suficiente. Y afirmo que insuficientemente porque aún no se ha llegado a una democracia plena, ni a un auténtico Estado de Derecho, ni mucho menos a un desarrollo económico y social accesible a todos los habitantes. El Congreso federal y los congresos estatales tienen un papel preponderante en la consecución de dichos fines. El derecho parlamentario auxiliará en esta noble y complicada tarea.

\section{v. Conclusiones}

Primera.- .A cien años de vigencia de la Constitución de 1917, se puede observar que la regulación del Poder Legislativo es muy distinta. Ha aumentado la importancia del mismo y su estatuto se ha ampliado, aunque no precisamente ha evolucionado positivamente en el ejercicio de sus funciones y en el equilibrio de poderes.

Segunda.- El Congreso General ha buscado mejorar la función legislativa, pero ha descuidado la función de control.

Tercera.- Los congresos estatales han perdido importancia y facultades que es ineludible recuperar y potencializar, para lograr un auténtico federalismo y un Estado de Derecho consolidado.

Cuarta.- El derecho parlamentario ha crecido en importancia en este siglo de vigencia de la Constitución, pero precisa seguir evolucionando para aportar nuevas soluciones a los problemas que día a día enfrenta la institución representativa.

“ELl federalismo ayuda a combatir el autoritarismo? Un análisis comparado entre el diseño constitucional de Estados Unidos y México", en CIfUREP. Textos furídicos y Políticos, Tlaxcala, México, Año 6, núm. 7, enero-junio 2018, Universidad Autónoma de Tlaxcala, ISSN 2395-9460, pp. 43-76 Disponible en: <http://garantismoyderechoshumanos.com.mx/Articulos/cargaArticulo/17-P>. 
Vi. Fuentes

1. Bibliografía

Bentham, Jeremy, Tácticas parlamentarias, prólogo de Gustavo Carvajal Moreno, México, Coordinación de los Diputados del Sector Popular del Partido Revolucionario Institucional, 2002.

CAarpizo, Jorge, "Concepto de democracia y sistema de gobierno en América Latina", en Boletín Mexicano de Derecho Comparado, México, Instituto de Investigaciones Jurídicas, UNAM. Nueva serie, año XL, No. 119, mayo-agosto, 2007.

Chávez Hernández, Efrén, "Algunas propuestas de modificación al formato del informe presidencial en México", en Boletín Mexicano de Derecho Comparado, México, Instituto de Investigaciones Jurídicas, UNAM. Nueva Serie, Año XXXV, No. 105, Septiembre-Diciembre, 2002. Disponible en: <https://revistas.juridicas.unam.mx/index.php/derecho-comparado/article/view/3733/4599>.

, El derecho parlamentario estatal mexicano: análisis y propuesta de reforma, México, UNAM, Instituto de Investigaciones Jurídicas, 2016, xvi, 359 páginas (Instituto de Investigaciones Jurídicas. Serie Doctrina Jurídica, 765). Disponible en: <https://biblio.juridicas.unam.mx/ bjv/detalle-libro/4236-el-derecho-parlamentario-estatal-mexicano-analisis-y-propuesta-de-reforma>.

“¿El federalismo ayuda a combatir el autoritarismo? Un análisis comparado entre el diseño constitucional de Estados Unidos y México", en CIfUREP. Textos furídicos y Políticos, Tlaxcala, México, Año 6, núm. 7, enero-junio 2018, Universidad Autónoma de Tlaxcala, ISSN 2395-9460, pp. 43-76 Disponible en: <http://garantismoyderechoshumanos.com.mx/Articulos/cargaArticulo/17-P $>$.

, "Ética en el Poder Legislativo", Boletín Mexicano de Derecho Comparado, México, Instituto de Investigaciones Jurídicas, UNAM, Nueva Serie, Año XXXIX, núm. 115, enero-abril, 2006. Disponible en: $<$ https://revistas.juridicas.unam.mx/index.php/derecho-comparado/article/view/3869/4851>. 
DAHL, Robert A., La democracia: una guía para los ciudadanos, traducción de Fernando Vallespín, Madrid, Taurus, 1999.

Garrorena Morales, A., "Parlamento", en Aragón Reyes, Manuel, Temas básicos de derecho constitucional; Tomo II: Organización del Estado, Madrid, España, Civitas, 2001.

Godoy, Luis, Reelección en la Cámara de Diputados, 1917-1934; Federalismo y ambición politica Tesis para obtener el título de la licenciatura en Ciencia Política, México, Instituto Tecnológico Autónomo de México, sin año, disponible en: <http://departamentodecienciapolitica.itam. $\mathrm{mx} /$ sites/default/files/u327/tesis_luis_godoy.pdf> (consultado noviembre de 2016).

Jefferson, Tomás, Manual del Derecho Parlamentario ó Resumen de las Reglas, prólogo de Augusto Gómez Villanueva, traducido por Joaquín Ortega, México, Talleres de Reproducciones OSVIC, 2002 [Edición facsimilar de la obra de 1827].

Ochoa Campos, Moisés (dir.), Derecho Legislativo Mexicano, dirigido y escrito en parte por Moisés Ochoa Campos, con la colaboración de Jorge Carpizo, Héctor Manuel Ezeta, Jorge Sayeg Helú y otros, México, XLVIII Legislatura del Congreso de la Unión, Cámara de Diputados, 1973.

Pedroza de la Llave, Susana Thalía, El Congreso General Mexicano. Análisis Sobre su Evolución y Funcionamiento Actual, México, Editorial Porrúa, 2003.

Quiroga Lavié, Humberto et al., Derecho parlamentario iberoamericano, México, Porrúa, Instituto de investigaciones legislativas, 1987.

Varios Autores, El Poder Legislativo federal y local en el marco de un nuevo federalismo. Encuentro Nacional de Comisiones de Reglamentos y Prácticas Parlamentarias u Homólogas, 18 de febrero de 2005, Colima, México, Cámara de Diputados, Comisión de Reglamentos y Prácticas Parlamentarias, 2005. 
Varios autores, Reforma y modernización del Poder Legislativo federal y local. Segundo Encuentro Nacional de Comisiones de Reglamentos y Prácticas Parlamentarias u Homólogas, 23 de septiembre de 2005, La Paz, Baja California Sur, México, Cámara de Diputados, Comisión de Reglamentos y Prácticas Parlamentarias, 2006.

Varios autores, Reformas urgentes al marco jurídico del Congreso mexicano, 2a. ed., México, Cámara de Diputados, LIX Legislatura, Comisión de Reglamentos y Prácticas Parlamentarias, 2006, 2 ts.

Wilson, Woodrow, El Gobierno Congresional. Régimen político de los Estados Unidos, México, Universidad Nacional Autónoma de México, 2002.

\section{Electrónicas}

"Constitución Política de los Estados Unidos Mexicanos, Publicación Original: DOF 05-02-1917", Página de internet de la Cámara de Diputados, disponible en: http://www.diputados.gob.mx/LeyesBiblio/ ref/cpeum/CPEUM_orig_05feb1917.pdf (consultado mayo de 2019).

"Constitución política de los estados unidos mexicanos; Constitución publicada en el Diario Oficial de la Federación el 5 de febrero de 1917. Texto vigente; Última reforma publicada DOF 15-052019", Página de Internet de la Cámara de Diputados, http://www.diputados.gob.mx/LeyesBiblio/ref/cpeum.htm (consultado mayo de 2019).

"Constitution Act, 1982", en A consolidation of the Constitution Acts 1867 to 1982, Ontario, Canada, Minister of Public Works and Government Services, 2012, pp. 65-66. Disponible en: http://lawslois.justice.gc.ca/PDF/CONST_E.pdf (consultado noviembre de 2016).

"La Constitución de los Estados Unidos de América 1787", Página de Internet de National Archives, https:/ /www.archives.gov/espanol/constitucion.html (consultado noviembre de 2016). 
LEGISLATURAS XXVII-LX (1917-2009); Diputados Integrantes, México, Cámara de Diputados del H. Congreso de la Unión, LX Legislatura, 2008, disponible en: http://www.diputados.gob.mx/sedia/ biblio/virtual/dip/leg27-60.htm (consultado noviembre de 2016).

"Ley Orgánica del Congreso General de los Estados Unidos Mexicanos", publicada en el Diario Oficial de la Federación el 03-09-1999; el "Reglamento para el Gobierno Interior del Congreso General de los Estados Unidos Mexicanos" de 20-03-1934; el "Reglamento del Senado de la República" del 04-06-2010; así como el "Reglamento de la Cámara de Diputados" de 24-12-2010.

México. Cámara de Diputados, "Reformas Constitucionales por Artículo; Última reforma publicada en el Diario Oficial de la Federación el 15 de mayo de 2019", Página de internet de la Cámara de Diputados, http://www.diputados.gob.mx/LeyesBiblio/ref/cpeum_art.htm (consultado mayo de 2019).

"Tercer Censo de Población de los Estados Unidos Mexicanos 1910", Página de internet del Instituto Nacional de Estadística y Geografia (INEGI), http://www.inegi.org.mx/est/contenidos/proyectos/ccpv/ cpv1910/ (consultado noviembre de 2016). 